\title{
Laura Verciani, Marie de l'incarnation. Esperienza mistica e scrittura di sé
}

\section{Monica Pavesio}

\section{(2) OpenEdition}

1 Journals

\section{Edizione digitale}

URL: http://journals.openedition.org/studifrancesi/27518

DOI: 10.4000/studifrancesi.27518

ISSN: 2421-5856

\section{Editore}

Rosenberg \& Sellier

\section{Edizione cartacea}

Data di pubblicazione: 31 décembre 2006

Paginazione: 597

ISSN: 0039-2944

\section{Notizia bibliografica digitale}

Monica Pavesio, «Laura Verciani, Marie de l'incarnation. Esperienza mistica e scrittura di sé », Studi

Francesi [Online], 150 (L | III) | 2006, online dal 30 novembre 2015, consultato il 08 novembre 2020.

URL : http://journals.openedition.org/studifrancesi/27518; DOI : https://doi.org/10.4000/

studifrancesi. 27518

Questo documento è stato generato automaticamente il 8 novembre 2020.

\section{(c)}

Studi Francesi è distribuita con Licenza Creative Commons Attribuzione - Non commerciale - Non opere derivate 4.0 Internazionale. 
Laura Verciani, Marie de l' incarnation. Esperienza mistica e scrittura di sé

Monica Pavesio 


\section{NOTIZIA}

LAURA VERCIANI, Marie de l'incarnation. Esperienza mistica e scrittura di sé, Firenze, Alinea

Editrice, 2004, pp. 223.

1 La letteratura spirituale conosce nel XVII secolo una straordinaria fortuna. Molti contemplativi, in prevalenza donne, sulla scia di Teresa d'Avila e Giovanni della Croce, narrano la propria vita interiore con la pratica dell'autobiografia, una forma di scrittura poco in voga nel Seicento.

2 Fra le numerose scrittrici mistiche francesi del XVII secolo, Laura Verciani ha dedicato uno studio approfondito agli scritti di Marie de L'Incarnation, l'orsolina fondatrice nel 1639 della prima missione femminile a Québec, che, a differenza di Teresa d'Avila, è stata fino ad oggi, unicamente oggetto di saggi teologici e dottrinali.

3 L'autrice prende in esame il complesso degli scritti autobiografici di Marie, composti da due relazioni spirituali del 1633 e del 1654 e da una fitta corrispondenza con laici e religiosi, che copre il lungo lasso di tempo compreso fra il 1626 ed il 1672.

Il rapporto con il figlio Claude, che Marie abbandonò undicenne per entrare in convento, la questione dell'identità e la rievocazione del vissuto spirituale sono i tre nodi problematici attorno ai quali si articola la scrittura mistica dell'orsolina, sui quali si è soffermata l'anali di Laura Verciani. Un paragrafo è dedicato al linguaggio particolare utilizzato per narrare l'esperienza mistica, un'appendice alle correzioni apportate ai testi materni dal figlio Claude, primo editore delle opere di Marie. Una dettagliata bibliografia conclude il volume. 